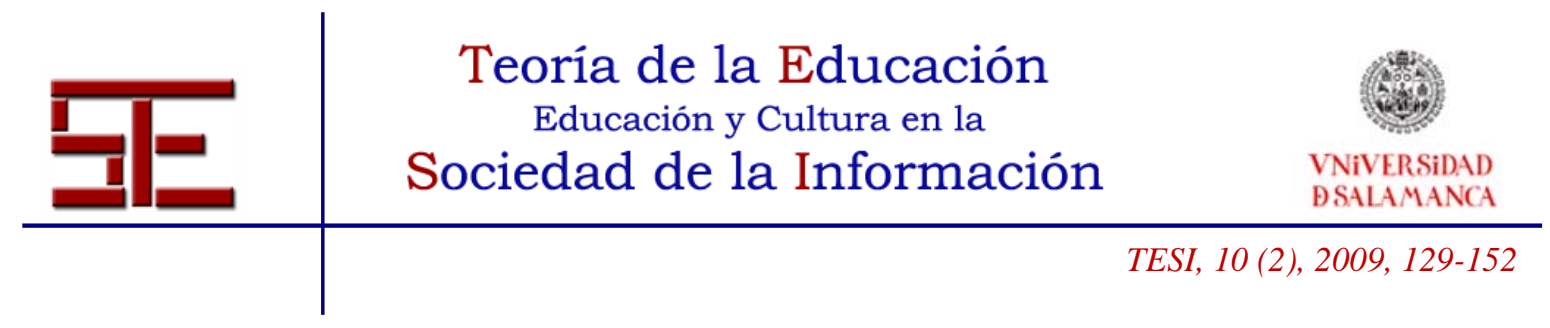

\title{
DIMENSIÓN FORMATIVA DE LA ALFABETIZACIÓN TECNOLÓGICA
}

Resumen: La alfabetización tecnológica en el marco actual de la Sociedad del Conocimiento tiene un papel esencial en la educación. El impacto de la tecnología en la vida de las personas es tan patente, que los profesionales de la educación han considerado que el conocimiento y uso adecuado de ésta, es un contenido educativo necesario que reconfigura el propio sistema educativo en relación al modelo de alumno, del formador y de todo el proceso de conocimiento. La importancia y la incidencia de la tecnología en la educación se ha convertido en una señal de progreso, calidad y mejora que abre nuevas perspectivas formativas y formas de aprendizaje que condicionan tanto nuestras vidas personales y profesionales como nuestros estilos de vida. En este contexto el papel del formador está sufriendo una transformación para dar respuesta a los nuevos retos y exigencias educativas y sociales que se plantean en el siglo XXI.

Palabras clave: alfabetización, formación, tecnología, sociedad del conocimiento, formador, gestión del conocimiento.

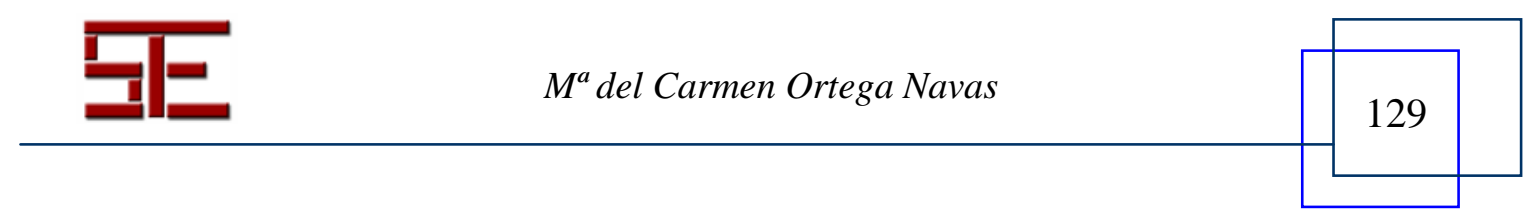




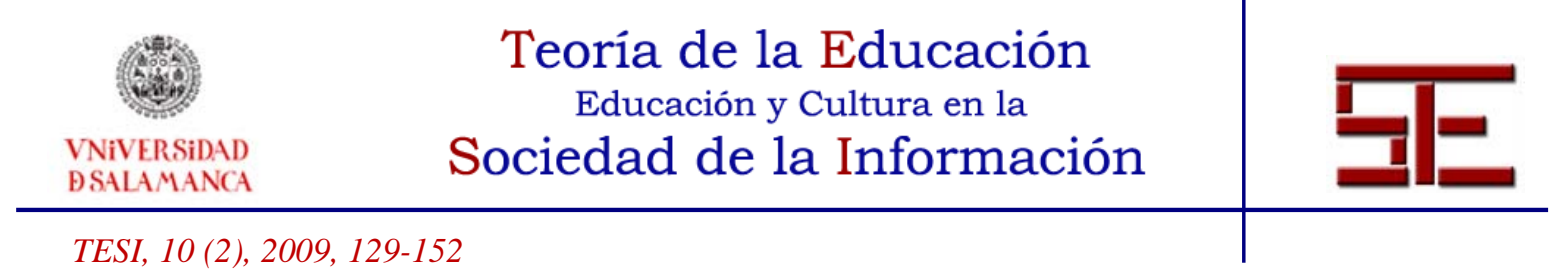

THE EDUCATIONAL DIMENSION OF TECHNOLOGICAL LITERACY

Abstract: Technological literacy in the context of today's Knowledge Society plays an essential role in education. The impact of technology on people's lives is so obvious that teaching professionals consider the knowledge and adequate use thereof to be a necessary ingredient of education, and one which reshapes the educational system itself with respect to the model of the educator, the student and the entire knowledge process. The importance and the impact of technology on education has become a sign of progress, quality and improvement that creates new educational perspectives and new ways of learning, shaping both our professional and personal lives as well as our lifestyles. In this context, the role of the educator is being transformed to respond to the new educational and social challenges and demands of the twenty-first century.

Key words: literacy, education, new technologies, knowledge society, educator, knowledge management.

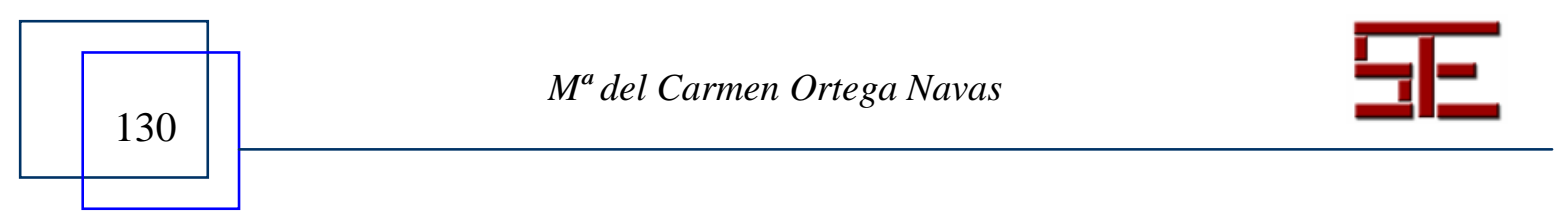




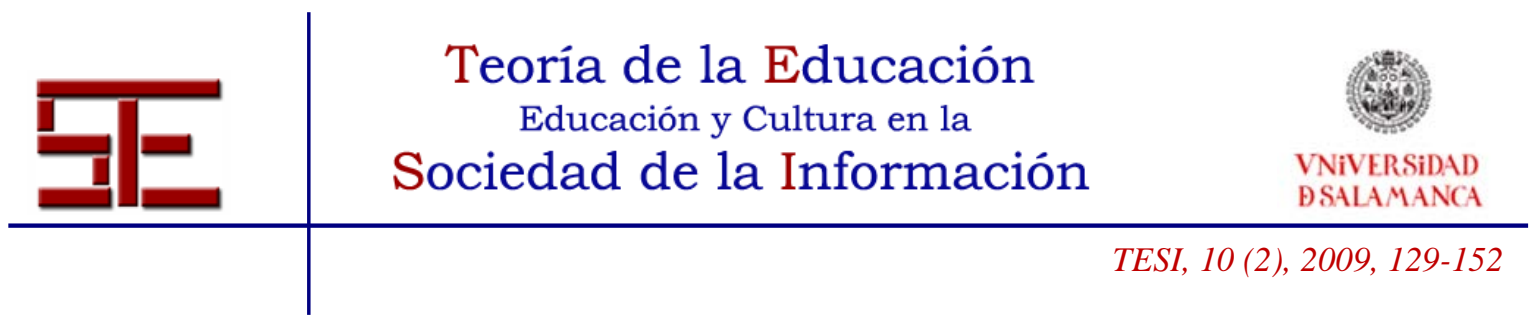

\section{DIMENSIÓN FORMATIVA DE LA ALFABETIZACIÓN TECNOLÓGICA}

María del Carmen Ortega Navas

cortega@edu.uned.es

Universidad Nacional de Educación a Distancia.

\section{1.- INTRODUCCIÓN.}

La alfabetización tecnológica es un fenómeno que nos afecta y desempeña un papel cada vez más importante en la evolución de nuestras sociedades actuales. Nunca, como hasta ahora el conocimiento de las nuevas tecnologías, entendiendo éstas como una serie de nuevos medios que nos permiten la organización de nuevos contenidos han despertado tanto interés y significado. De hecho, el avance vertiginoso de las nuevas tecnologías de la información y la comunicación (TIC) están cambiando nuestra manera de entender y vivir la realidad cotidiana.

La alfabetización tecnológica abre nuevas posibilidades al implicar un cambio en la producción, procesamiento, organización y transmisión de nuevos contenidos. Además se considera que la alfabetización tecnológica debe ser entendida como un factor de desarrollo en las personas, en primera instancia, y en la sociedad en general, que implica nuevas exigencias en la educación básica de las personas intentando acercar la realidad al proceso educativo.

Cada vez somos más conscientes que el auge de las tecnologías en nuestros días condiciona nuestras vidas como motores de cambio y de nuevas perspectivas en el mundo educativo. Así, las nuevas tecnologías se han convertido, en el ámbito educativo, en un apoyo importante y en un contenido educativo con una gran relevancia social, actuando como medios y recursos didácticos de información que permiten procesar y transformar la información.

Partiendo de la premisa de que nuestra sociedad en general y los entornos formativos en particular son y serán, cada vez, más tecnológicos hemos de referirnos a cómo los formadores y los discentes deberán contar con unas mínimas competencias para desenvolverse en ellos. En consecuencia la formación en las nuevas tecnologías de la información y la comunicación se ha convertido en un requisito imprescindible para sobrevivir en la sociedad del siglo XXI. Aún más, la alfabetización tecnológica implica "un prerrequisito de ciudadanía en la sociedad del conocimiento y del desarrollo

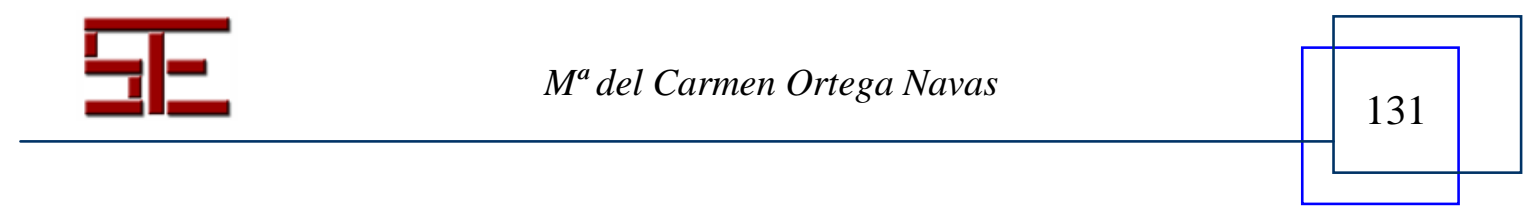




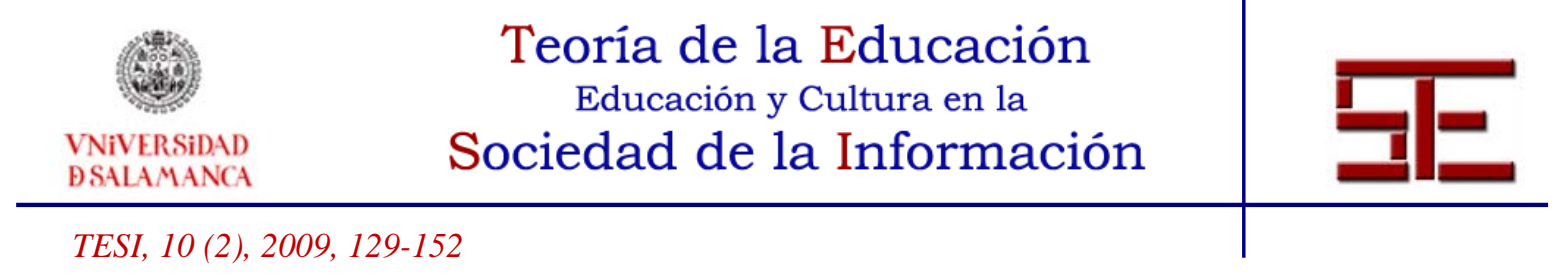

profesional en la economía del conocimiento. Su contrapartida, la brecha digital, se concibe como una barrera al desarrollo personal y social, y como una divisoria social de la misma importancia que la economía” (Gutiérrez, 2002, 25).

Al definir la dimensión formativa de alfabetización tecnológica pretendemos hacer alusión a las contribuciones formativas del uso de las herramientas tecnológicas, para que las personas se desenvuelvan más satisfactoriamente en una sociedad cada vez más tecnológica, que demanda de personas más preparadas y capacitadas para afrontar los retos que presenta la actual Sociedad del Conocimiento otras veces conocida como Sociedad de la Información.

Las posibilidades que nos aportan las nuevas tecnologías de la información y del conocimiento, no solo como "herramienta" sino como un nuevo contenido formativo o como una nueva forma de comunicación e interacción son, entre otras, la mejora de los procesos de adquisición y organización de los conocimientos, la mejora de las capacidades de juicio crítico y la forma de entender y comprender la realidad, el perfeccionamiento de la calidad del aprendizaje de las personas y el cambio en la relación docente-discente.

De hecho, no podemos olvidar tampoco que el impacto tecnológico está incidiendo en tareas relacionadas con la formación y la educación, lo cual implica como hemos aludido anteriormente, una modificación de los roles tradicionales tanto para los formadores como para los alumnos, generando igualmente, nuevas formas de aprendizaje y abriendo nuevas oportunidades para el desarrollo del ejercicio profesional.

Con este artículo pretendemos resaltar la importancia de cómo la alfabetización tecnológica abre nuevas perspectivas formativas para la educación. Igualmente, pretendemos incitar a la reflexión sobre las implicaciones y consecuencias de los cambios tecnológicos en la educación de la actual sociedad del siglo XXI y dar respuesta al interrogante sobre lo que aportan las nuevas tecnologías al proceso educativo como fuente de desarrollo humano, de oportunidades e integración social.

A continuación pasamos a realizar una breve aproximación conceptual y legislativa de la alfabetización tecnológica, para continuar con la incidencia de la alfabetización tecnológica como recurso para la formación de las personas.

\section{2.- FUNDAMENTACIÓN TEÓRICA}

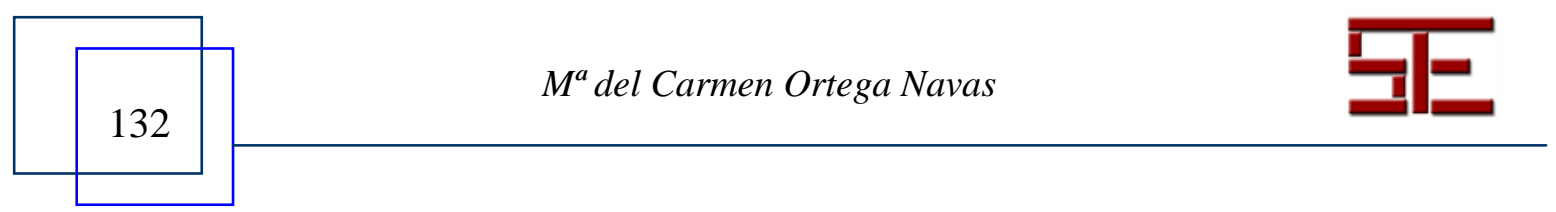




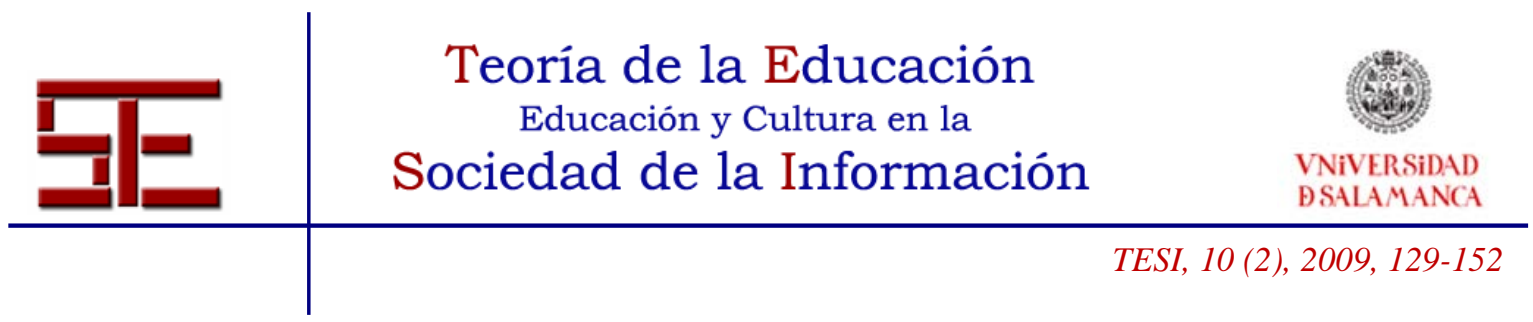

La alfabetización es uno de los derechos fundamentales de todo ser humano. De acuerdo con el artículo 26 de la Declaración de los Derechos Humanos de 1948 "toda persona tiene derecho a la educación”. En consecuencia las personas en la actual Sociedad del Conocimiento requieren de nuevas competencias para poder desarrollarse personal y profesionalmente.

Las definiciones de alfabetización en el estado actual de la cuestión en el momento presente son numerosas. La mayoría de ellas, en esencia, hacen alusión a la capacidad de las personas para entender y comunicarse a través de los textos escritos. No obstante, hoy la alfabetización se extiende a otras áreas de conocimiento como las ciencias y la tecnología.

La definición del concepto alfabetización ha ido transformándose a lo largo de los años. A lo largo de los siglos XIX y XX el concepto inicial de alfabetización hacía referencia a la capacidad de dominio de técnicas instrumentales básicas de acceso al conocimiento escrito o impreso (lectura, escritura y cálculo). En nuestros días el concepto de alfabetización está cambiando radicalmente, puesto que la falta de conocimientos en el dominio de las nuevas tecnologías está creando una nueva forma de analfabetismo.

El acercamiento de las personas a las nuevas tecnologías de la información y el conocimiento se ha venido definiendo con un amplio abanico semántico del concepto básico que ha evolucionado a nuevas formas de alfabetización, tales como, la alfabetización digital, alfabetización funcional, alfabetización informática y alfabetización tecnológica, entre otras. No obstante, en esta ocasión nos centraremos en la definición del concepto alfabetización tecnológica entendida como la capacidad de buscar, encontrar, ordenar, categorizar, organizar y aplicar la tecnología de la información para el uso personal y profesional.

La alfabetización tecnológica se refiere no solamente al hecho del saber leer y escribir sino al entendimiento y utilización de la información para que las personas puedan llegar a ser competentes en la compresión y solución de problemas de un modo analítico y comprensivo, desarrollando una postura reflexiva y crítica frente a las situaciones de la vida diaria. En consecuencia, podemos mantener que hoy tan necesario como aprender a leer y escribir, es adquirir las destrezas que permitan codificar, interpretar y traducir los múltiples lenguajes que ofrece nuestra cultura, de lo contrario, las personas

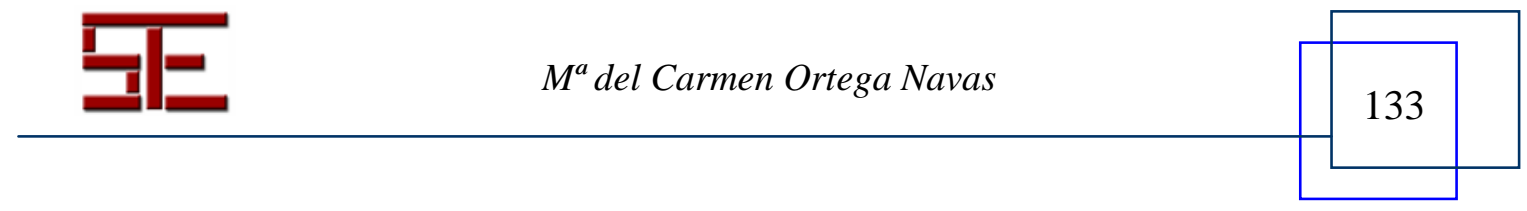




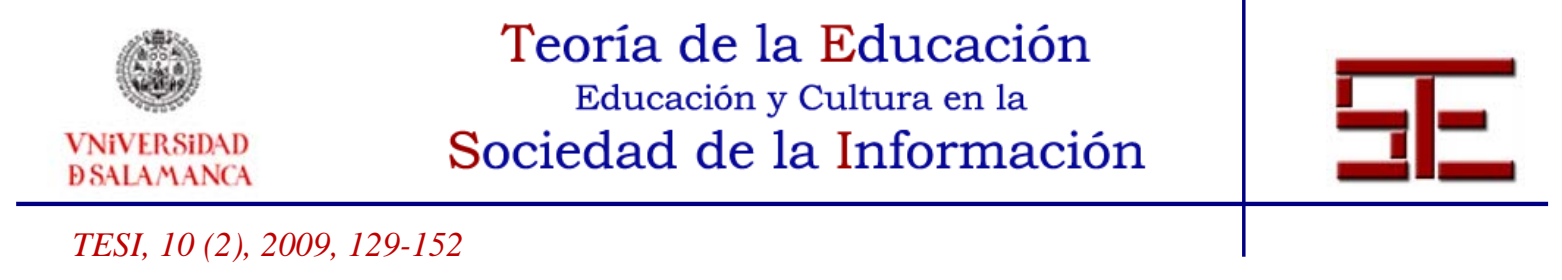

se verían abocadas a soportar consecuencias tales como la inadaptación e incluso la exclusión social.

Cabe destacar que inicialmente de acuerdo con Fourez (1997) los orígenes del concepto alfabetización tecnológica se derivan del concepto alfabetización científica, concepto que surge a su vez por la necesidad de que las personas se adecuen a su entorno.

Además hemos de mencionar que el concepto alfabetización se acuñó para referirse a la adquisición de competencias que capacitan a las personas a utilizar las nuevas tecnologías y que incluye la alfabetización informática y la alfabetización digital.

Mientras que algunos autores como Bawden (2002) y Lynch (1998) entienden que la alfabetización tecnológica es parte de la alfabetización informacional. Otros autores como es el caso de Bigum y Green (1992) entienden que la alfabetización tecnológica hace referencia a los ambientes de alfabetización digital, o lo que es lo mismo al uso y conocimiento del manejo de ordenadores, agendas electrónicas, sistemas gps, entre otros. También Bigum y Green (1992) entienden que el concepto de alfabetización tecnológica se divide en cuatro categorías: la tecnología para la alfabetización, alfabetización para la tecnología, la alfabetización como tecnología y la tecnología como alfabetización.

Nosotros entendemos que la alfabetización tecnológica consiste en la adquisición de conocimientos y habilidades cognitivas e instrumentales con relación al manejo de las nuevas tecnologías, así como al desarrollo de valores y actitudes con relación a las tecnologías que surge como necesidad de hacer frente a la desinformación en el uso y aplicación de las nuevas tecnologías en el desempeño en la vida social y productiva de las personas.

Por otra parte, queremos resaltar que los estudios sobre el impacto de los nuevos instrumentos tecnológicos en la educación se han venido sucediendo desde mediados de los años ochenta del siglo pasado. Así, en los últimos años un sinfín de avances tecnológicos han intentado abrirse paso en el ámbito educativo, tales como la televisión interactiva, el ordenador, el video, la radio, la pizarra digital y los multimedias, entre otros. En este contexto se entiende que una persona no está alfabetizada cuando carece de las habilidades necesarias para acceder a las nuevas tecnologías, o lo que es lo mismo, no posee conocimientos sobre el manejo técnico de las tecnologías que le permitan buscar, seleccionar, comprender, elaborar, analizar y difundir la enorme cantidad de información a la que se accede a través de las nuevas tecnologías.

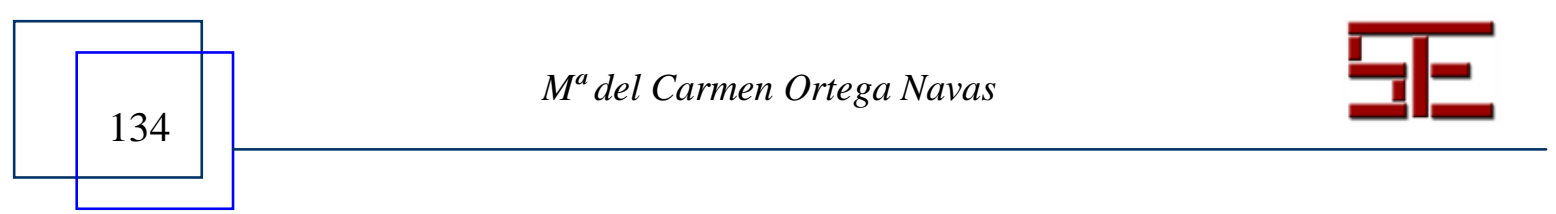




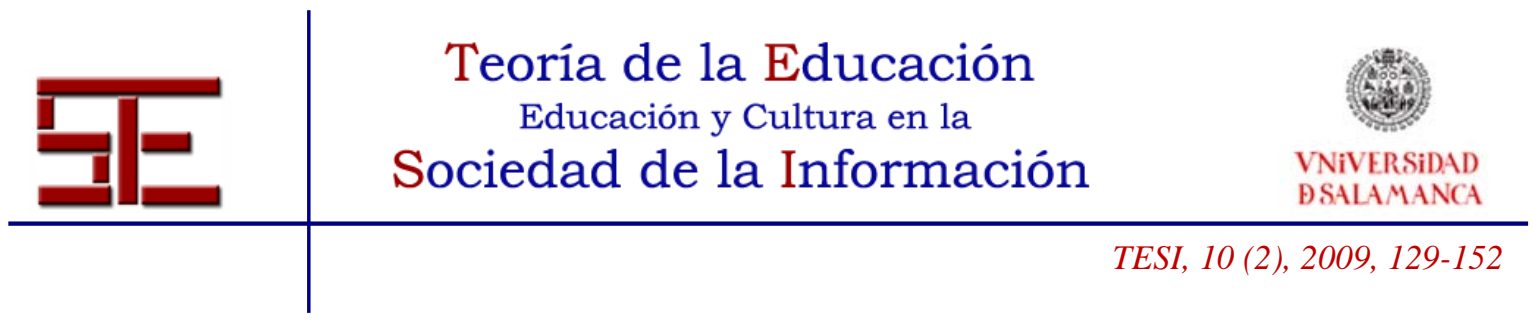

\section{3.- LA ALFABETIZACIÓN TECNOLÓgICA DESDE LAS PROPUESTAS LEGISLATIVAS DE LOS ORGANISMOS OFICIALES}

En la sociedad globalizada en la que nos encontramos inmersos, se hace dada día más necesario una educación centrada en las nuevas formas de aprendizaje basadas en las nuevas tecnologías para alcanzar los objetivos políticos y sociales. En este contexto la alfabetización tecnológica se ha convertido en un tema recurrente en la política social nacional y europea. Basta con mirar algunos de los documentos legislativos del sistema educativo español y de numerosos organismos oficiales y organizaciones intergubernamentales que prestan su apoyo y colaboración a actividades de alfabetización tecnológica como la Unión Europea, el Consejo de Europa, la UNESCO y la OCDE, entre otros, para encontrar alusión directa o indirectamente a la alfabetización tecnológica y a las nuevas tecnologías.

De hecho, el impacto que las nuevas tecnologías dejan sentir en la sociedad actual, queda patente en las diferentes políticas de los distintos entes gubernamentales, por ejemplo en el caso concreto de la UNESCO, la alfabetización se ha convertido en una de las prioridades educativas.

Muchas son las aportaciones que en materia legislativa aluden a la alfabetización tecnológica. En las próximas páginas presentaremos una breve aproximación a las contribuciones relativas a la introducción de nuevas tecnologías en la educación desde los organismos y documentos oficiales.

\section{1.- A nivel nacional}

Es oportuno resaltar algunas de las disposiciones legales, dadas en nuestro país, sobre la necesidad de alfabetización de las personas en las nuevas tecnologías. Destacamos sin pretender ser exhaustivos, entre otras, las siguientes:

La Ley Orgánica de la Calidad de la Educación (LOCE) (BOE 24 de diciembre de 2002) en la Exposición de motivos reconoce que "los cambios tecnológicos han transformado las sociedades modernas en realidades complejas, afectadas por un fuerte dinamismo que tiene en el conocimiento y en la información el motor del desarrollo económico y social". Insiste además, en que la educación se encuentra hoy en "el centro de los desafíos y de las oportunidades de las sociedades del siglo XXI”.

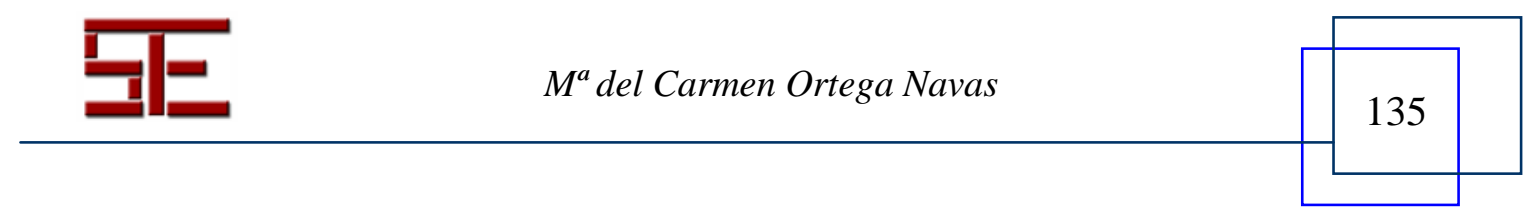




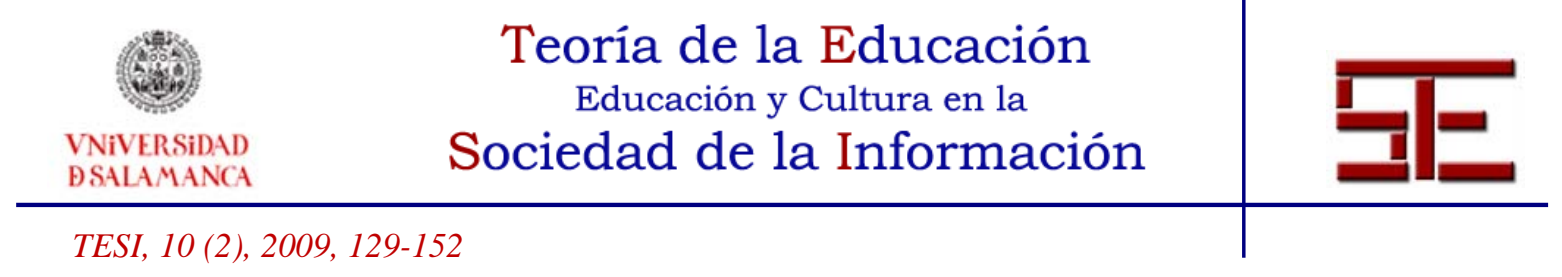

En el documento del Ministerio de Educación y Ciencia Una Educación de calidad para todos y entre todos. Informe del debate (2005) se señala en el apartado correspondiente a las enseñanzas de las tecnologías de la información y de la comunicación que dichas enseñanzas son "necesarias en la sociedad actual pero no son la panacea. Es ineludible un planteamiento global y crítico de la integración de las tecnologías de la información y la comunicación en la educación partiendo de un marco teórico que contemple su definición en tres aspectos más importantes: técnicos, comunicativos y psicodidácticos” (MEC, 2005, 67).

La nueva Ley Orgánica de Educación (LOE) (BOE 4 de mayo de 2006) en su preámbulo alude a la necesidad de que la educación responda a las necesidades de la sociedad actual de acuerdo a los avances globales de la sociedad. De la educación y del impacto de la tecnología y la evolución acelerada del conocimiento sigue insistiendo, como un valor creciente, dependen el bienestar individual y colectivo.

En suma desde las Leyes de Educación en el Estado Español se reconoce la importancia de la alfabetización en las nuevas tecnologías mediante las distintas posibilidades que se ofrecen desde el sistema educativo.

\section{2.- A nivel europeo}

La alfabetización tecnológica implica un compromiso de los gobiernos de diferentes países y de algunos organismos, tales como los que hemos aludido anteriormente, la UNESCO, las Naciones Unidas y las Organizaciones intergubernamentales para establecer como mensaje prioritario en las sociedades avanzadas la necesidad de alfabetización tecnológica con el objetivo de que ésta sea alcanzada por y para todos. En la resolución del Consejo de las Comunidades Europeas y de los ministros de Educación reunidos en el seno del Consejo de 19 de septiembre de 1983, sobre las medidas relativas a la introducción de nuevas tecnologías de la información en la educación se planteaba que es cada vez más importante que "la escuela familiarice a los jóvenes con las nuevas tecnologías de la información con el fin de asegurar mejores oportunidades a las generaciones futuras".

En el informe de la Comisión creada por la UNESCO, presidida por Jaques Delors, La educación encierra un tesoro (1996) mantiene que "las nuevas tecnologías están generando ante nuestros ojos una verdadera revolución que afecta tanto a las actividades

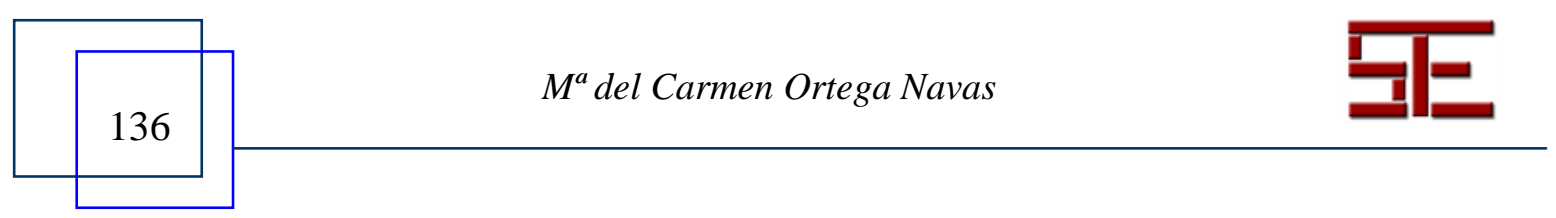




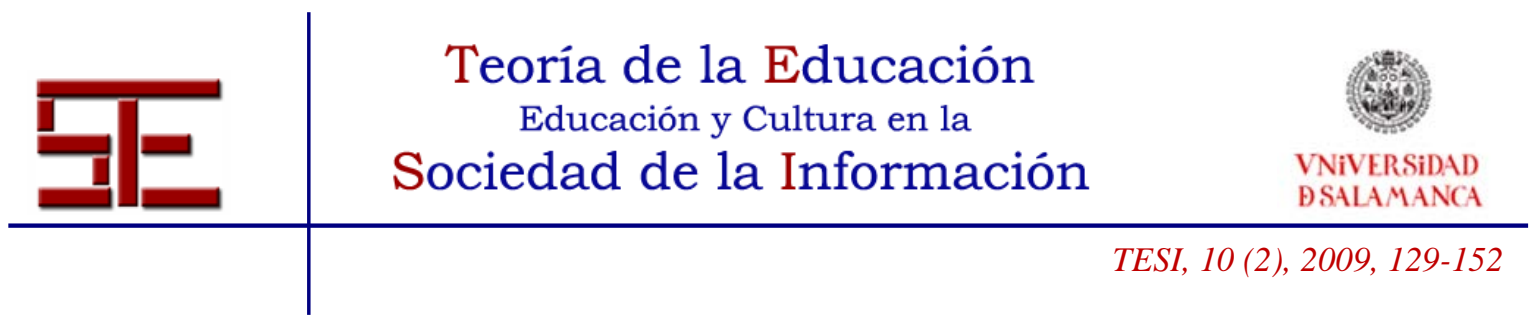

relacionadas con la producción y el trabajo como las actividades ligadas a la educación y la formación”.

La UNESCO en la Conferencia Mundial sobre la Ciencia para el siglo XXI: Un nuevo compromiso (1999) promueve la alfabetización tecnológica como prioritaria dentro de los países e invita a las Naciones Unidas y a Organizaciones gubernamentales a colaborar con dicha acción mediante planes especiales para cada tipo de nación. Igualmente sostiene en su Anexo 1 sobre la Declaración sobre la ciencia y el uso del saber científico que "hoy más que nunca es necesario fomentar y difundir la alfabetización científica en todas las culturas y en todos los sectores de la sociedad [...] a fin de mejorar la participación de los ciudadanos en la adopción de las decisiones relativas a la aplicación de los nuevos conocimientos”. Igualmente se afirma la importancia de la ciencia al servicio del desarrollo de manera que "la ciencia y la tecnología también deben orientarse decididamente hacia un mejoramiento de las posibilidades de empleo, la competitividad y la justicia social”. Igualmente se postula que el "desarrollo de actitudes científicas y tecnológicas, tiene que ver con las habilidades que son necesarias para enfrentarse a un ambiente que cambia rápidamente y que son útiles para resolver problemas, proponer soluciones y tomar decisiones sobre la vida diaria”.

El Consejo Europeo Extraordinario de Lisboa (marzo 2000) en su documento Hacia la Europa de la innovación y el conocimiento manifiesta que entre los objetivos prioritarios en la actual sociedad del conocimiento cabe destacar el aumento del conocimiento de las personas de las cualificaciones más básicas, es decir, de la alfabetización en las tecnologías.

También durante el foro Mundial sobre la Educación celebrado en Dakar (Senegal) en abril 2000 en el documento titulado Educación para Todos: cumplir nuestros compromisos comunes se alude a que las tecnologías van a contribuir decisivamente al logro de los objetivos de la educación y que "el rápido avance de las TIC y su creciente generalización y difusión, así como la índole de sus contenidos y reducción de costos, están repercutiendo en el aprendizaje de manera considerable”.

Al año siguiente en el informe emitido por la UNESCO Decenio de las Naciones Unidas para la Alfabetización (diciembre 2001) se afirmaba que "en el mundo en rápida evolución de la actual sociedad del conocimiento, en el que se utilizan progresivamente medios de comunicación tecnológicos más nuevos e innovadores, los conocimientos

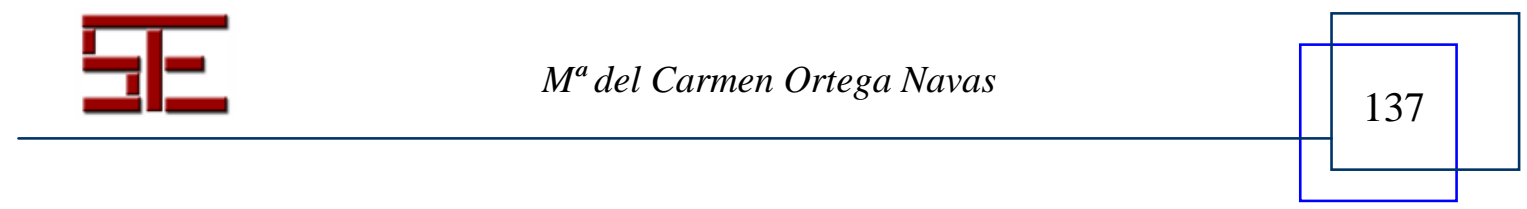




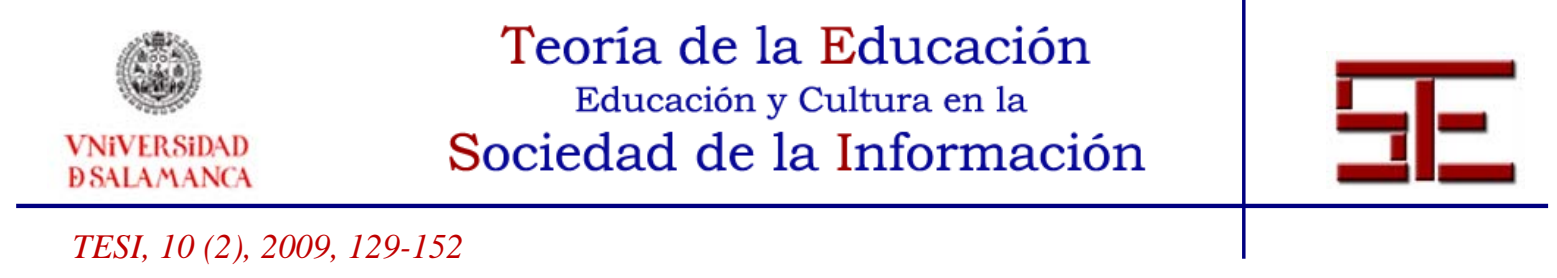

que se exigen siguen aumentando sin cesar [...]. Insiste además que a fin de poder sobrevivir en el mundo globalizado de hoy, "todas las personas deben adquirir nuevos conocimientos y desarrollar la capacidad de localizar, evaluar y utilizar de manera eficaz información de múltiples maneras”.

La importancia de la alfabetización tecnológica queda constatada también en la dos Cumbres Mundiales de la Sociedad de la Información organizadas por la ONU celebradas en Ginebra en (2003) y en Túnez (2005). En la declaración de principios se afirma que "somos conscientes de que las TIC deben considerarse un medio, y no un fin en sí mismas. En condiciones favorables, estas tecnologías pueden ser un instrumento eficaz para acrecentar la productividad, generar crecimiento económico, crear empleos y fomentar la ocupabilidad, así como mejorar la calidad de la vida de todos”.

Por último cabe destacar que la UNESCO está coordinando el proyecto de Alfabetización en la Década de las Naciones Unidas de 2003 a 2012, cuyo objetivo es demostrar que las personas alfabetizadas en el mundo serán más antes del año 2012. Además la UNESCO ha realizado un proyecto llamado Estándares UNESCO de Competencia en TIC para Docentes (ECD-TIC) que facilita una guía importante para docentes y educadores. Este proyecto de la UNESCO, publicado en enero de 2008, es una orientación para que los docentes y educadores se formen adecuadamente sobre las nuevas tecnologías y puedan transmitir su conocimiento eficazmente a sus educandos. El objetivo general del proyecto, además de mejorar la práctica de los educadores y sus estrategias pedagógicas, es que se utilicen las nuevas tecnologías para mejorar la calidad de la educación.

\section{4.- EL FORMADOR Y LA ALFABETIZACIÓN TECNOLÓGICA}

El Informe Mundial de Educación del año 1998, Los Docentes y la Enseñanza en un Mundo en Mutación, afirma que la integración de las tecnologías tiene repercusiones en las modalidades de interacción entre formadores y alumnos en la formación a lo largo de toda la vida.

El formador debe ser consciente de que el mundo educativo demanda nuevos retos formativos como consecuencia de las revoluciones tecnológicas de nuestros días. El entorno en el que tiene lugar actualmente la enseñanza y la formación es cada vez más dinámico y complejo debido precisamente al desarrollo de las nuevas tecnologías. Por lo tanto, se hace necesario que el formador adquiera los conocimientos suficientes e

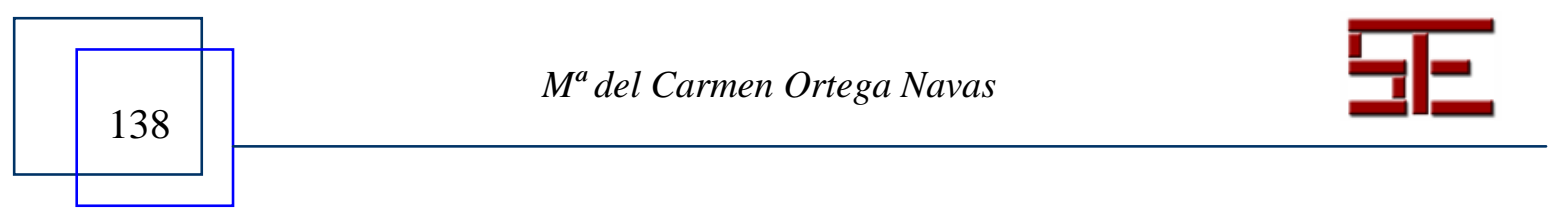




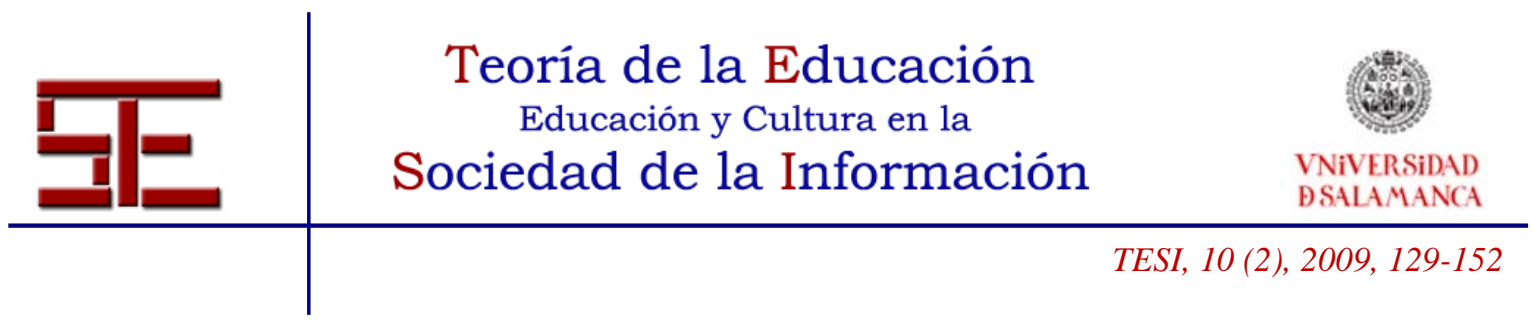

imprescindibles en el uso de las nuevas tecnologías, así como una actitud positiva hacia éstas. De acuerdo con Gómez Hernández, $(2000,8)$ en el ámbito de la formación es "un reto integrar las nuevas tecnologías, de modo que mejore el rendimiento y la calidad de la práctica educativa y responder eficazmente a las demandas formativas”.

Con la generalización del uso de las nuevas tecnologías, están apareciendo nuevas competencias que los formadores deben dominar (Bélisle y Linard, 1996). De hecho, en la actualidad se hace necesario un nuevo perfil de formador que se ajuste a los nuevos modelos educativos y desarrolle nuevos roles en consonancia con las exigencias y expectativas de la realidad circundante.

El formador hoy en día sigue desempeñando un papel clave en el modelo educativo, de hecho es el encargado de guiar el proceso de aprendizaje. La responsabilidad del formador es la actualización del contenido del conocimiento, de manera que los formadores "han de establecer las estrategias necesarias para la identificación, captura, recuperación, compartimiento y evaluación del conocimiento empresarial o de la organización” (López-Barajas, 2006, 252).

El formador deberá contribuir a que los alumnos adquieran las competencias y habilidades en el uso de las nuevas tecnologías necesarias para que puedan continuar aprendiendo de forma autónoma a lo largo de toda la vida. El alumno una vez adquiridas dichas competencias deberá poder utilizar los recursos digitales a su alcance para generar los conocimientos necesarios en cada situación y contexto.

La formación del formador en las nuevas tecnologías de la información y la comunicación es la clave fundamental de la transformación en las escuelas de cara a que los alumnos aprovechen las posibilidades educativas que éstas proporcionan. No debemos olvidar que las nuevas tecnologías han pasado a constituir "una potentísima herramienta pedagógica que permite mejorar y complementar la tradicional formación presencial” (Ortega Navas, 2006, 236).

El papel del formador, como hemos mencionado con anterioridad, ha cambiado sustancialmente al igual que las estrategias de formación virtual que sitúan al alumno en primer término del proceso para convertirse en un facilitador en la búsqueda de los recursos educativos necesarios y convertirse, por tanto, en un guía y consejero sobre fuentes apropiadas de información y un creador de hábitos y destrezas en la búsqueda, selección y tratamiento de la información.

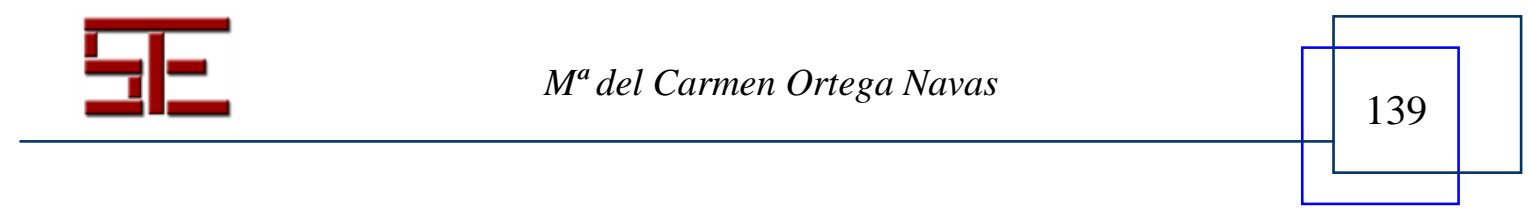




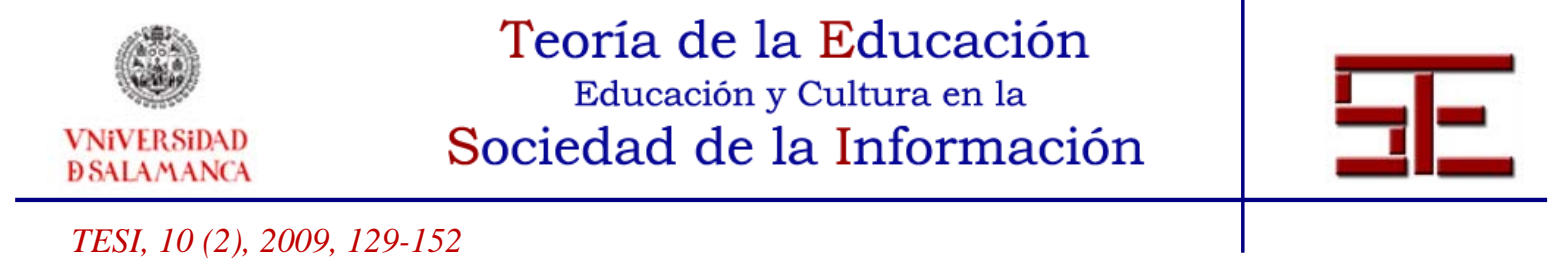

El formador será, además, el encargado de enseñar a sus alumnos no sólo sobre cómo llevar a cabo la búsqueda de la información, sino cómo evaluar la calidad de la misma. También el formador enseñará a sus alumnos a desarrollar un espíritu de trabajo en equipo para aprender unos de otros y lograr un aprendizaje más enriquecedor y participativo. Así de acuerdo con Touriñan (2001), citado en Colás (2003, 33) el papel fundamental del formador en estos nuevos entornos es el de actuar "de guía e instrumento del aprendizaje significativo a través de la Red [...]. El formador se convierte en un gestor de la formación [...] el que se ocupa de gestionar las capacidades, habilidades y conocimientos de los aprendices, detectando, motivando y aprovechando tanto individualmente como colectivamente sus posibilidades de aprendizaje”.

Cabe destacar que el formador deberá ayudar al discente a gestionar sus conocimientos puesto que como decíamos con anterioridad hoy no basta sólo con la adquisición de conocimientos sino que se hace imprescindible el aprender a seleccionar la información, organizarla y aplicarla de modo que la gestión del conocimiento, no es tanto "una tarea propia de la tecnología cuanto la cultura de la organización y desde la perspectiva de la formación, es un complejo o amalgama de conocimientos, experiencias, actitudes, aptitudes e intereses. Queremos significar que si las herramientas son necesarias aún más importantes es saber cómo usarlas” López-Barajas (2006, 246).

Ortega Sánchez $(2006,486)$ habla también de la generación del conocimiento tras el acceso a la información y la comunicación, destacando la importancia de la educación permanente para que las personas en la actual sociedad adquieran las competencias básicas de aprendizaje "incluyendo una nueva alfabetización tecnológica y digital que implique no sólo una capacitación instrumental de las tecnologías sino la transformación de la información en conocimiento aprendiendo a gestionarlo”.

De igual manera Roig Vila $(2002,160)$ afirma que el formador y resto de la sociedad deberán conocer, utilizar y valorar las nuevas tecnologías como un recurso para mejorar y enriquecer el proceso de enseñanza y aprendizaje. Igualmente postula que el formador deberá desarrollar estrategias para integrar las nuevas tecnologías a su práctica docente, "porque estos recursos son herramientas poderosas de apoyo, son materiales didácticos motivadores, sociabilizadores y potencian distintas habilidades (lingüísticas, comunicacionales, racionales y artísticas) que permiten tanto el intercambio entre profesores como entre alumnos”.

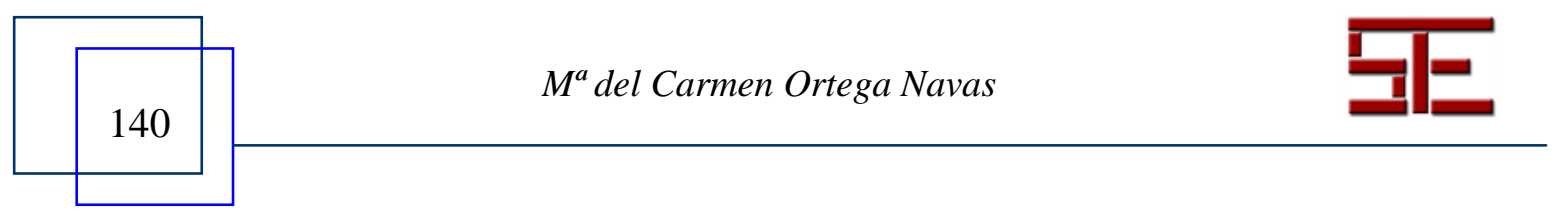




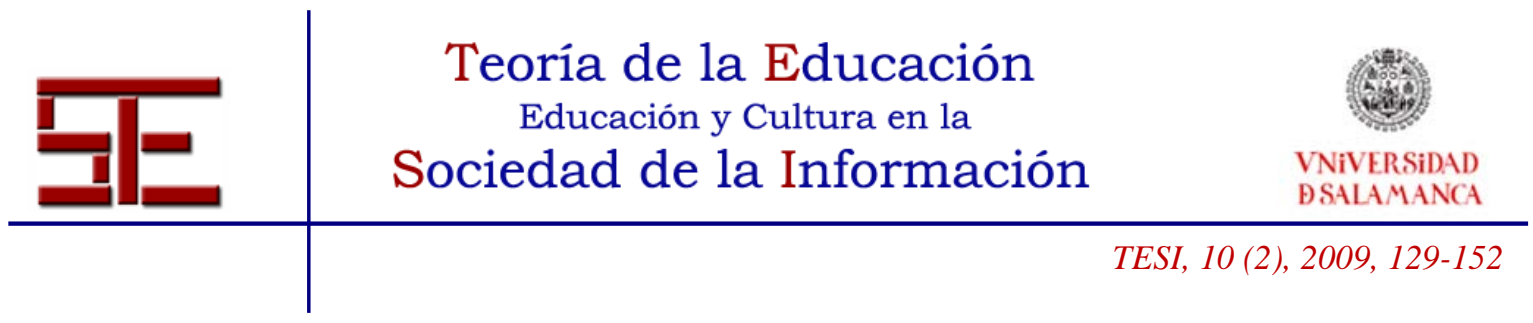

En suma, es innegable que el formador, en nuestros días, debe tomar conciencia de que la formación de un individuo en la sociedad actual no puede pensarse si ésta no incluye una preparación para convivir y gestionar las nuevas tecnologías de la información y la comunicación.

\section{5.- LA ALFABETIZACIÓN TECNOLÓGICA COMO RECURSO PARA LA FORMACIÓN}

La incorporación de las nuevas tecnologías al ámbito educativo es un tema de investigación por parte de numerosos expertos Rodríguez Díeguez y Sáenz Barrio (1995), Alonso y Gallego (1996), Tejada (1999), Cabero (2000), Rios y Cebrián de la Serna (2000), Echeverría (2001), Esteve (2003) y García del Dujo et al. (2004), entre otros.

Las personas tienen que afrontar e integrarse en esta sociedad en la que tienen que aprender a convivir con las tecnologías para sobrevivir, son "hijos de la tecnología” que están creciendo al ritmo del rápido devenir de su tiempo. Las nuevas tecnologías, en palabras de Ortega Navas $(2006,229)$ están incidiendo en "la transformación de los sistemas educativos al implicar nuevos retos y posibilidades en el ámbito de la enseñanza”.

Las posibilidades formativas de las nuevas tecnologías han sido objeto de estudio detenido y cuidado. Así en el informe de la UNESCO, por parte de la Comisión Internacional sobre la Educación para el siglo XXI titulado La educación encierra un tesoro coordinado por Delors (1996) sostiene que las posibilidades que aportan y las ventajas que ofrecen las nuevas tecnologías son numerosas y que repercuten en prácticamente todos los aspectos de nuestras vidas.

Las nuevas tecnologías de la información y de la comunicación conforme a García de Dujo, Martín García y Pérez Grande $(2004,66)$ "se muestran como recursos culturales y como cultura [...] como espacios de acción donde se construye y reconstruye la cultura y el conocimiento y donde se afianza el aprendizaje”.

La utilización de la tecnología con fines educativos favorece nuevas dimensiones y posibilidades en los procesos de enseñanza-aprendizaje en general. Como contrapunto a las aportaciones de las tecnologías se pueden plantear aportaciones, limitaciones e

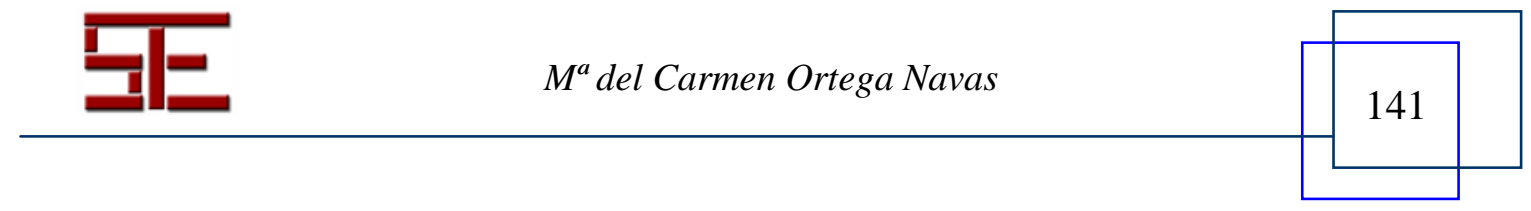




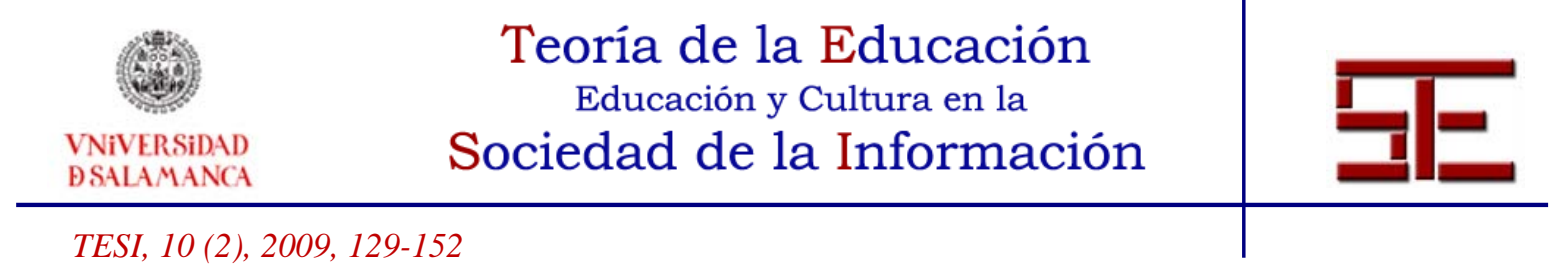

inconvenientes asociadas a la utilización de las nuevas tecnologías que pasamos a exponer a continuación.

\section{1.- Aportaciones formativas asociadas a la utilización de las nuevas tecnologías}

Las posibilidades que las tecnologías proporcionan a las personas y a su formación son innumerables. La alfabetización tecnológica ayuda y facilita el proceso formativo de las personas mediante el uso de la tecnología de un modo adecuado que se traducirá en un progreso personal, social y profesional más completo.

Partiendo del hecho de que la figura del formador es insustituible, podemos decir que las nuevas tecnologías abren un amplio abanico de posibilidades para los educandos, que de otra manera no serían posibles. De hecho, las nuevas tecnologías han cambiado el modo de trasmitir los conocimientos y el modo de enseñar a aprender en el que el formador era un mero trasmisor de conocimientos y del educando como un simple receptor de los conocimientos. Sus aportaciones son evidentes, entre las cuáles pasamos a enumerar las siguientes:

- Facilita el desarrollo de habilidades y conocimientos tecnológicos.

- Favorece una mayor autonomía y flexibilización del proceso formativo adecuándolo a las necesidades individuales.

- Aumenta la motivación de la persona al permitir presentar la información desde múltiples manifestaciones.

- Permite reducir las distancias físicas, temporales y geográficas entre docentes y discentes, flexibilizando así el tiempo y el espacio en el que se desarrolla la acción educativa, o lo que es lo mismo, que los alumnos sigan su propio ritmo de aprendizaje.

- Mejora y complementa la tradicional formación presencial.

- Ofrece una mayor variedad de ofertas educativas para que el discente pueda manipular el conocimiento de acuerdo a sus intereses y necesidades.

- Facilita a los discentes una formación actualizada.

- Despierta una mayor actitud crítica y pluralista en la actual sociedad en la que la mayoría del conocimiento que nos llega lo hace a través de las tecnologías.

- Modifica los roles tradicionales del formador y del alumno. El formador se convierte en un facilitador, mediador y dinamizador del aprendizaje, colaborador, tutor, participante del proceso de aprendizaje y guía de los recursos que ofrecen las tecnologías. Será el responsable de enseñar a los discentes sobre

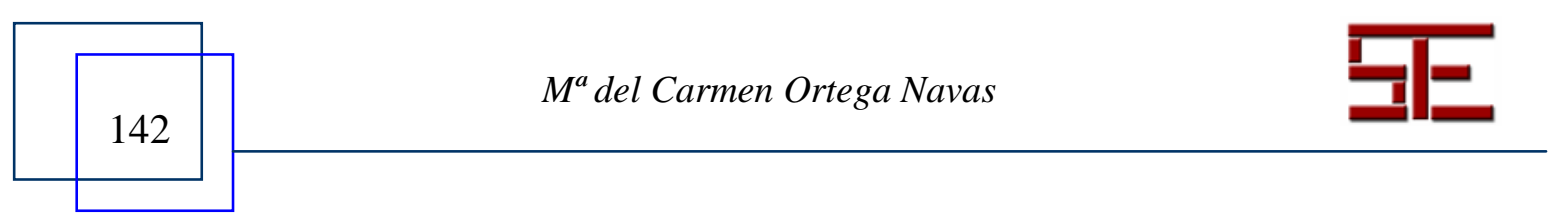




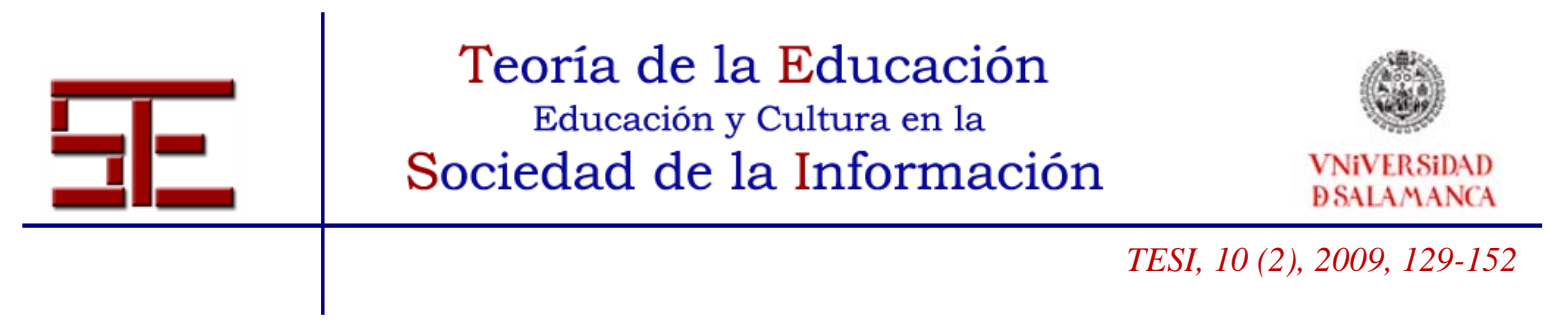

cómo llevar a cabo la búsqueda de la información y cómo evaluar la calidad de la información encontrada. Por su parte, el alumno se convierte en el protagonista activo en la adquisición, búsqueda, selección y procesamiento de conocimientos en un ambiente muy rico de formación.

- Incrementa el grado de aplicación de los conocimientos adquiridos.

- Desarrolla una actitud positiva de cara a un aprendizaje futuro más autónomo.

- Fomenta la creatividad.

- Fomenta los entornos interactivos y más flexibles para el aprendizaje.

- Aumenta las modalidades educativas.

- Favorece el compaginar el aprendizaje individualizado con el trabajo colaborativo y en grupo, lo cual motiva y estimula el aprendizaje.

- Favorece la enseñanza activa, participativa y constructiva.

- Facilita la formación permanente.

- Facilita la movilidad laboral.

- Permite la posibilidad de que las personas se sientan los responsables del diseño de su itinerario formativo.

Por último señalamos que de acuerdo con Barbera $(2001,59)$ la actuación del formador con la repercusión de las nuevas tecnologías en su actuación profesional le convierten en un animador que dirige su actuación hacia "el acompañamiento y gestión del aprendizaje; incitación al cambio de conocimientos, mediación relacional y simbólica o al pilotaje personalizado de los recorridos del aprendizaje”.

\section{2.- Limitaciones e inconvenientes formativos asociados a la utilización de las nuevas tecnologías}

Las nuevas tecnologías también contribuyen a que se planteen algunas limitaciones e inconvenientes formativos asociados a su utilización, entre ellos destacamos los siguientes:

- Disminución del tiempo de comunicación entre las personas.

- Desbordamiento cognitivo por la cantidad de información a la que la persona tiene acceso. Se produce una dispersión en la información, generándose una situación en la que el alumno al sentirse desbordado necesite una "sobreestimulación” para actuar.

- Limitan la expresión de formadores y alumnos como consecuencia de disminuir la interacción visual y directa entre ellos.

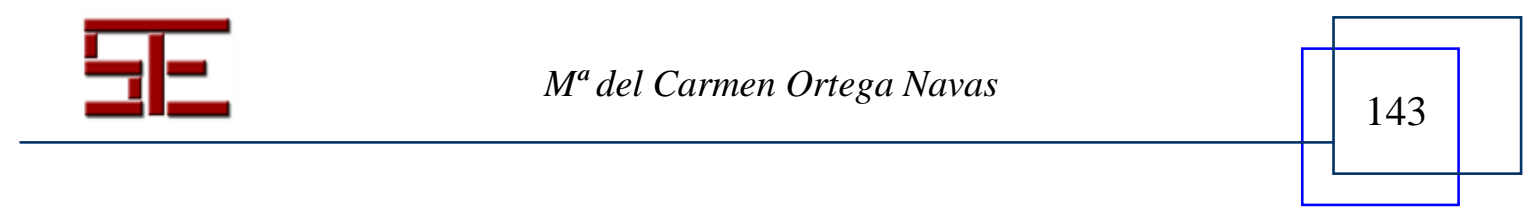




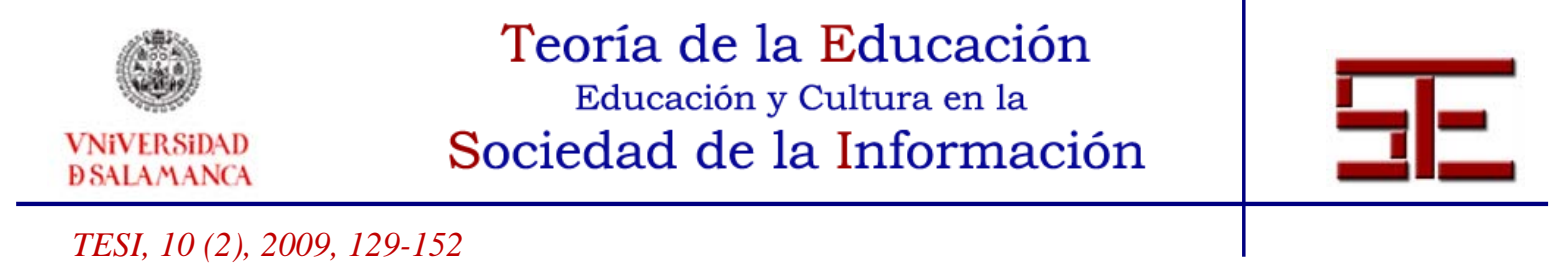

- Favorece la falta de familiaridad con ciertos medios lo que conlleva una posible pérdida de motivación y aumento de la tasa de abandonos.

- Favorece el sentimiento de inseguridad en las personas al no dominar las nuevas tecnologías.

- Incrementa el acceso desigual a las oportunidades de la sociedad civil dependiendo del grado de desarrollo de los países, lo que se traduce en una mayor diferencia en los países de desarrollo, pobreza y exclusión social.

En suma la alfabetización tecnológica como recurso para la formación y el desarrollo de las nuevas tecnologías está contribuyendo por un lado a la activación económica y social pero por otro implica una "brecha digital" de aquellas personas que no han tenido ocasión de adquirir conocimientos informáticos y familiarizarse con ellos, encontrándose en una situación menos ventajosa con respecto a aquellos que si han tenido posibilidades de acceso. Así de acuerdo con Sebastián y Sánchez $(2000,28)$ las nuevas tecnologías en nuestras vidas pueden ser un arma de doble filo, “está generando una modificación de los perfiles profesionales en muchos ámbitos laborales con nuevas exigencias de cualificación, de formación y de competencias profesionales. Se habla ya de un teleanalfabetismo que ya se está convirtiendo en una brecha, en un factor de diferenciación de las personas”.

A continuación, presentamos una tabla relacionada con el estado de la cuestión sobre" la brecha digital" en la que se recogen los resultados de la encuesta que ha llevado a cabo el Instituto Nacional de Estadística (INE) en el año 2007 sobre el Equipamiento y Uso de las Tecnologías de Información y Comunicación en la población española en las distintas Comunidades Autónomas. Esta encuesta se viene realizando desde el año 2002 en nuestro país.

El objetivo de la misma es la obtención de datos del desarrollo de lo que se ha denominado Sociedad de la Información mediante el análisis de la implantación y uso de las tecnologías de la información y de la comunicación en los hogares españoles. Las variables de clasificación utilizadas para el estudio han sido el tamaño del hogar, el sexo, la edad, el nivel de estudios y la relación con la situación laboral.

Las variables analizadas son: las personas conectadas a Internet todos los días o al menos una vez por semana, las personas que viven digitalmente, es decir, aquéllas que utilizan Internet como medio de comunicación activa a través de foros, redes sociales, listas de distribución, correo electrónico, etc., las personas que son productores y

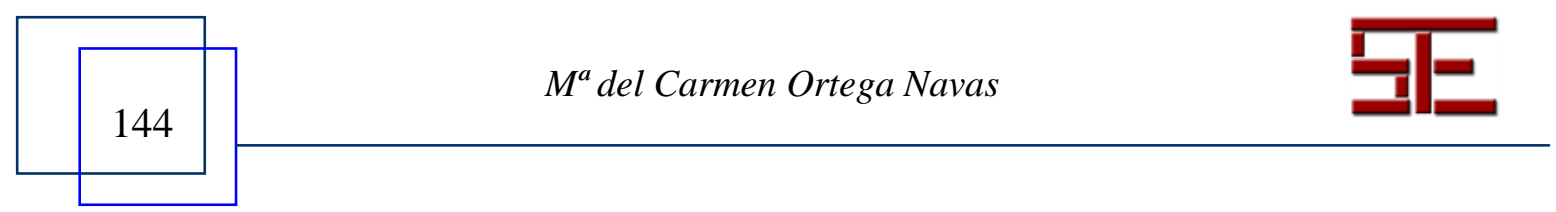




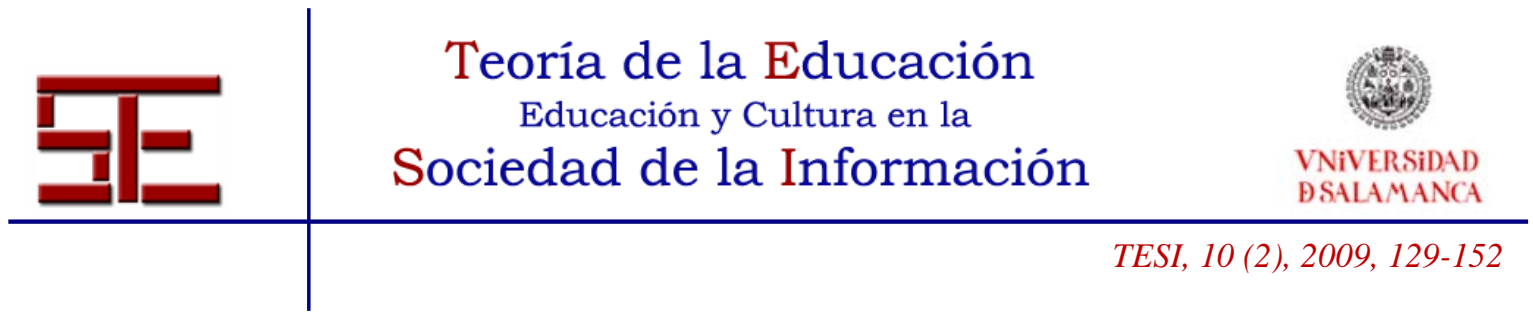

consumidores de la información (Prosumers) y las personas jóvenes que han integrado e interactúan con las tecnologías de una manera natural y que cada vez constituyen un grupo más importante (Nativos digitales). Las unidades de los datos presentados son porcentajes de personas.

\begin{tabular}{|ccccc|}
\hline $\begin{array}{c}\text { Comunidad Autó- } \\
\text { noma }\end{array}$ & Conectados & $\begin{array}{c}\text { Viven digital- } \\
\text { mente }\end{array}$ & Prosumer & Nativos digitales \\
\hline Andalucía & 28,68 & 20,15 & 5,74 & 3,40 \\
Aragón & 34,84 & 19,06 & 6,25 & 3,24 \\
Asturias & 34,79 & 19,99 & 6,98 & 3,47 \\
Baleares & 38,28 & 22,21 & 5,75 & 2,97 \\
Canarias & 33,79 & 23,25 & 5,51 & 3,19 \\
Cantabria & 34,26 & 18,99 & 5,53 & 2,98 \\
Castilla la Mancha & 26,23 & 16,50 & 4,84 & 3,02 \\
Castilla y León & 32,68 & 19,44 & 7,30 & 3,99 \\
Cataluña & 38,17 & 21,30 & 6,73 & 3,57 \\
Ceuta & 27,42 & 18,20 & 5,32 & 2,88 \\
C. Valenciana & 31,90 & 19,92 & 5,38 & 3,01 \\
Extremadura & 21,94 & 16,21 & 4,64 & 2,84 \\
Galicia & 26,28 & 16,05 & 5,26 & 3,23 \\
\hline Madrid & 43,79 & 25,87 & 10,74 & 5,34 \\
Melilla & 41,12 & 34,87 & 16,30 & 10,34 \\
Murcia & 27,80 & 18,32 & 5,30 & 2,88 \\
Navarra & 34,21 & 15,91 & 5,41 & 2,59 \\
País Vasco & 30,18 & 12,53 & 4,34 & 2,25 \\
Rioja & 32,37 & 16,78 & 5,25 & 2,90 \\
\hline TOTAL & $\mathbf{3 3 , 4 1}$ & $\mathbf{2 0 , 2 0}$ & $\mathbf{6 , 4 9}$ & $\mathbf{3 , 5 4}$ \\
\hline
\end{tabular}

Tabla 1. Equipamiento y Uso de las Tecnologías de Información y Comunicación en la población española en las distintas Comunidades Autónomas (2007)

Fuente: http://www.genisroca.com/2007/

\section{6.- REFLEXIONES FINALES}

Las nuevas tecnologías forman parte de la sociedad. La Sociedad del Conocimiento está sujeta a nuevos retos y uno de ellos es precisamente potenciar la alfabetización tecnológica de las personas. No obstante, aunque se ha avanzado mucho en el ámbito de la alfabetización tecnológica, aún queda mucho por hacer. En un futuro no muy lejano el conocimiento de las posibilidades que ofrecen las nuevas tecnologías se considerará

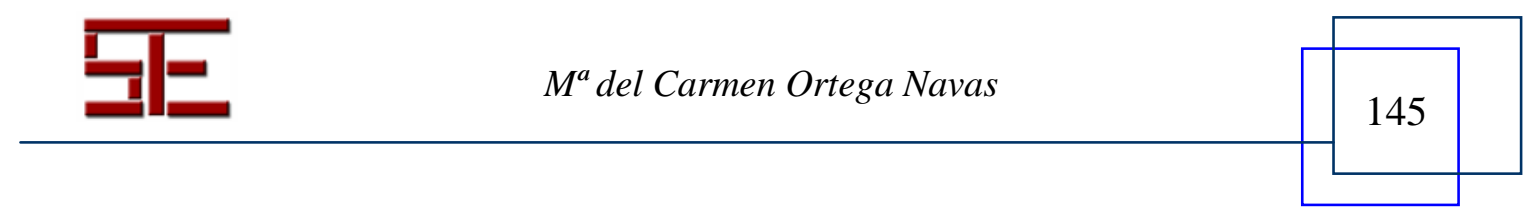




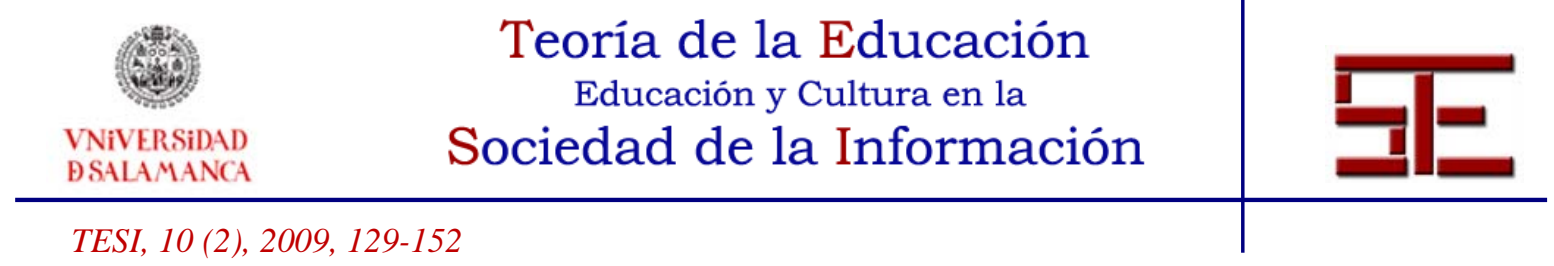

una habilidad básica que las personas deberán desarrollar para facilitar su progreso y bienestar en todos los ámbitos de la vida.

Tenemos que tener presente que es innegable que la formación de un individuo en la sociedad actual no puede pensarse si ésta no incluye una preparación para convivir con las nuevas tecnologías de información y comunicación. Por ello, es necesario cada vez más incrementar las propuestas de formación que permitan capacitar, actualizar e incorporar al sistema de competencias laborales a profesionales y técnicos mediante el uso de las nuevas tecnologías de información y comunicación.

Tampoco debemos perder de vista que en las sociedades actuales las nuevas tecnologías han tomado un papel predominante como instrumento al servicio de la educación por ser un contenido esencial de la educación, por su contribución en la mejora de la calidad del proceso formativo y por ser una vía fundamental para la difusión del conocimiento.

Relacionado con lo anterior nos encontramos con que la aparición y auge de las nuevas tecnologías de la información y de la comunicación, ha contribuido a aumentar y facilitar el acceso e intercambio de la información; y como en cada periodo de la historia en el cual se ha producido un cambio o "revolución" en el modo de acceder al conocimiento, las personas que lo viven experimentan un proceso de acomodación pertinente a las necesidades del momento puesto que de no hacerlo sus posibilidades de progreso personal, social y económico se verían mermadas.

Cabe destacar que es obvio que en nuestra sociedad cada vez más se precisan de personas competentes en el conocimiento de las tecnologías, o lo que es lo mismo, no podemos pensar que la formación de las personas no incluya una formación que les capacite para su convivencia con las nuevas tecnologías de información y comunicación. Para lo cual, ahora más que nunca se hace necesario una formación de formadores en las nuevas tecnologías que les permita ayudar a responder a las personas ante los retos y exigencias sociales que se le plantean en este siglo XXI y que les capaciten, por tanto, para que éstas estén en sintonía con los cambios sociales, políticos, culturales y económicos que se dan en la sociedad en general. De lo contrario, una persona analfabeta tecnológicamente se quedará al margen de las ofertas educativas que las nuevas tecnologías les proporcionan y serán susceptibles de quedar excluidos socialmente en una sociedad globalizada en la que el conocimiento se ha convertido en una potente herramienta competitiva. Igualmente las personas que no estén formadas en las nuevas tecnologías se encontrarán, en consecuencia, con más dificultades para acceder al mercado profesional y laboral.

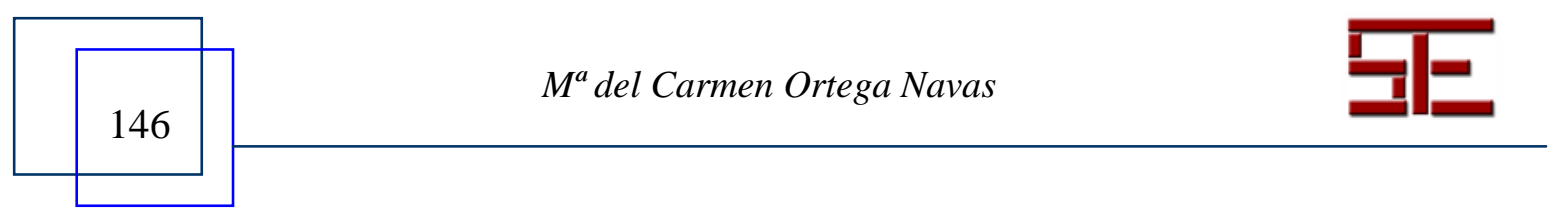




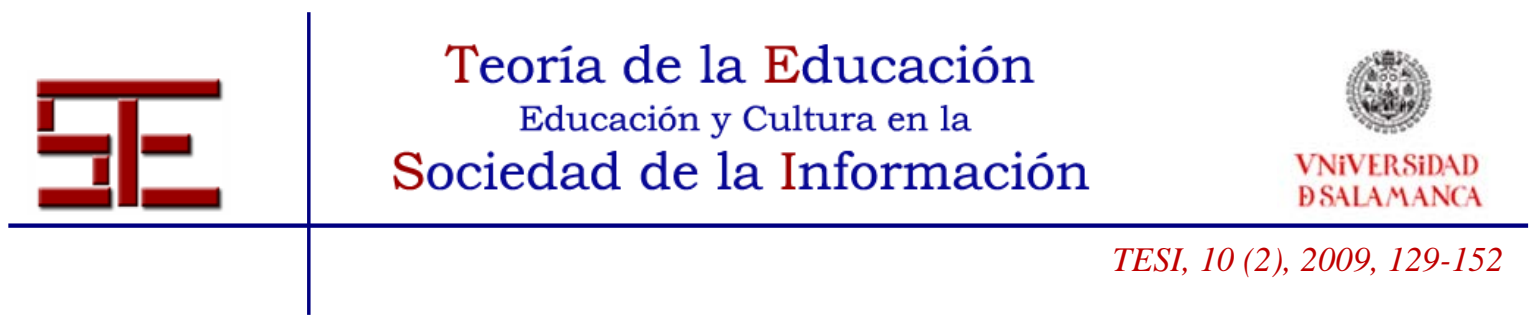

Finalmente hemos de indicar que una de las claves y retos de la formación en la Sociedad del Conocimiento será que las personas adquieran las competencias para el aprender a aprender a lo largo de la vida, así como aprender a enfrentarse a la búsqueda, selección, elaboración, y difusión de la información de manera que les cualifiquen laboralmente para el uso de las nuevas tecnologías de la información y comunicación, desarrollando además, una actitud positiva y crítica hacia las nuevas tecnologías. Esto se traducirá no solamente en la incorporación de las nuevas tecnologías en los sistemas educativos, sino también en el cambio de roles del formador, cambios en el modo de aprendizaje de las personas, cambios en las organizaciones e instituciones y cambios en las modalidades de acceso y tutorización en la formación. De hecho, como ya hemos mencionado con anterioridad la actual Sociedad de la Información en la que nos encontramos inmersos demanda una mayor cultura tecnológica en general que contribuya a la mejora de la calidad del aprendizaje facilitando el acceso de las personas a servicios y recursos para participar activa y libremente en su entorno.

A modo de conclusión de todo lo expuesto, cabe señalar que las nuevas tecnologías se han convertido es una de las áreas prioritarias en la actual sociedad, constituyéndose la alfabetización tecnológica en un aspecto imprescindible, sin duda, para lograr el progreso y bienestar personal, profesional, social, económico, cultural y político de las personas y de la sociedad en general. De hecho, las posibilidades de desarrollo de una persona y de la sociedad van a venir condicionadas más por su capacidad para crear, difundir y utilizar los conocimientos, que por sus riquezas naturales.

No queremos concluir sin reiterar una vez más que la dimensión formativa de la alfabetización tecnológica es hoy más que nunca un elemento clave para mejorar la calidad de la educación, lo cual va a contribuir, sin duda, a que las personas aprendan a enfrentarse a los cambios tecnológicos actuales con mejores garantías para la vida en cualquier situación y contexto.

\section{BIBLIOGRAFÍA}

ALONSO, C. M. y GALLEGO D. J. (1996): Los educadores ante el reto de las Tecnologías de la Información y Comunicación. Madrid, UNED.

BARBERÁ, E. (coord.) (2001): La incógnita de la educación a distancia. Barcelona, ICE-Horsori.

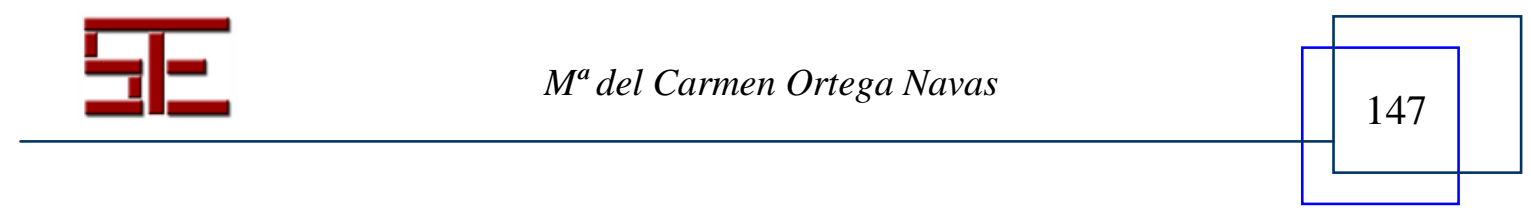




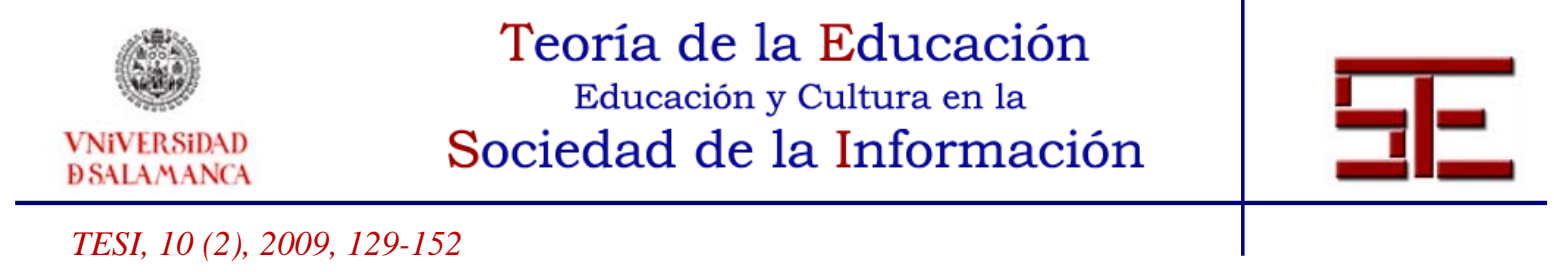

BADWEN, D. (2001): Information and Digital Literacy: A review of concepts, Journal of Documentation, 57, (2), 218-259.

BAWDEN D. (2002): Revisión de los conceptos de alfabetización informacional y alfabetización digital, Anales de Documentación (5), 361-408.

BÉLISLE, C. y LINARD, M. (1996): Quelles nouvelles compétences des acteurs de la formation dans le contexte de TIC, Revista Education Permanente, 127, 19-47.

BIGUM, C. Y GREEN, B. (1992): Technologizing literacy: the dark side of the dreaming, Discourse, 12, (2), 4-28.

CABERO, J. (2000): El rol del profesor ante las nuevas tecnologías de la información y comunicación, Agenda Académica, 7, (1), 41-57.

CABERO, J. (2001): Tecnología educativa. Barcelona, Paidós.

COLÁS, M M P. (2003): Internet y Aprendizaje en la sociedad del conocimiento, Comunicar, 20, 31-35.

COMISIÓN DE LAS COMUNIDADES EUROPEAS (2000): Concebir la educación del futuro: promover la innovación con las nuevas tecnologías. Bruselas, Comisión de las Comunidades Europeas.

COMISIÓN DE LAS COMUNIDADES EUROPEAS (2002): Decisión del Parlamento Europeo y del Consejo por la que se adopta un programa plurianual (2004-2006) para la integración efectiva de las tecnologías de la información y la comunicación (TIC) en los sistemas de educación y formación en Europa (programa eLearning). Bruselas, Comisión de las Comunidades Europeas.

COMPAINE, B.M. (2001): The Digital Divide. Facing a crisis or creating a myth? Cambridge, MIT Press.

DELORS, J. (1996): La educación encierra un tesoro. Informe a la UNESCO de la Comisión Internacional sobre la educación para el siglo XXI. Madrid, Santillana.

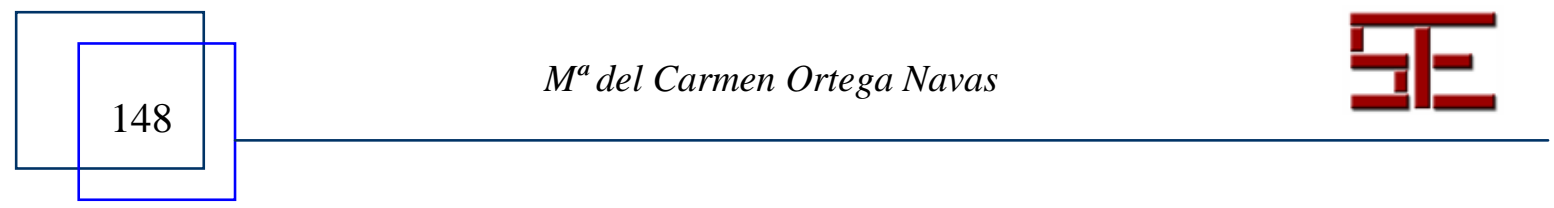




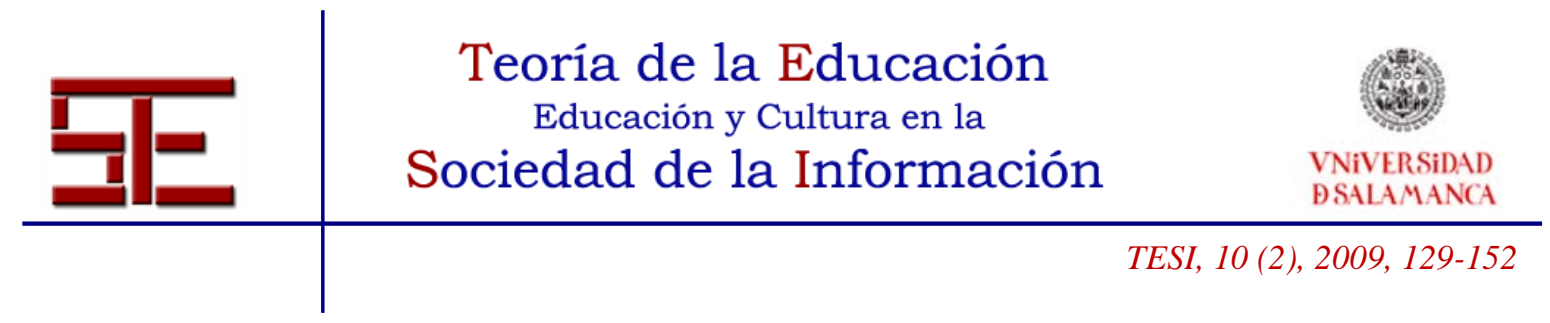

ECHEVERRÍA, J. (2001): Educación y nuevas tecnologías: El Plan Europeo eLearning, Revista de educación, número extraordinario, 201-210.

ESTEVE, J.M. (2003): La tercera revolución educativa. La educación en la sociedad del conocimiento. Barcelona, Paidós.

EDRYDICE (2001): Basic indicators on the incorporation of ITC into European Education Systems: Annual Report 2000-01. Brusels, Technical Report.

FOUREZ, G. (1997): Alfabetización científica y tecnológica. Acerca de las finalidades de la enseñanza de las ciencias. Buenos Aires, Ediciones Colihue.

GARCÍA DEL DUJO, Á. MARTÍN GARCÍA, A. y PÉREZ GRANDE, M.D. (2004): Procesos de formación on- line. Salamanca, Amarú Ediciones.

GÓMEZ HERNÁNDEZ, J.A. (Coord.) (2000): Estrategias y modelos para enseñar a usar la información: Guía para docentes, bibliotecarios y archiveros. Murcia,KR.

GUTIÉRREZ, M. (2002): Alfabetización tecnológica: competencias básicas para una nueva cultura, Dirección General de Universidades: Perspectivas de aplicación y desarrollo de las nuevas tecnologías de la Educación, Madrid, MECD, 23-30.

LÒPEZ-BARAJAS, E (2006): Estrategias para a gestión del conocimiento, en LÒPEZBARAJAS, E. et al. (2006): Estrategias de formación en el siglo XXI. Barcelona, Ariel, 245-264.

LYNCH, C. A. (1998): Information Literacy and Information Technology Literacy:

New Components in the Curriculum for a Digital Culture: Committee on Information Technology Literacy.

LYNCH, M. y LANG, M. (2004): The Online Educator. A Guide to Creating the Virtual Classroom, Education and Information Technologies, 9 (1), 91-93.

MARTÍNEZ FRANCISCO, P. E. (2004): Nuevas Tecnologías en Educación. Madrid, Pearson Educación: Prentice Hall.

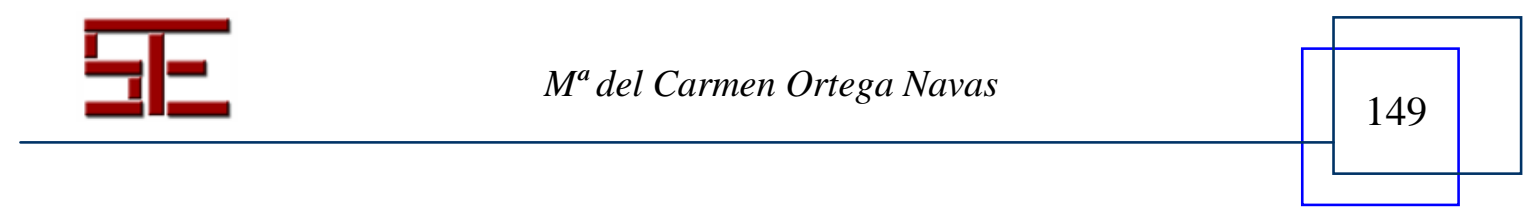




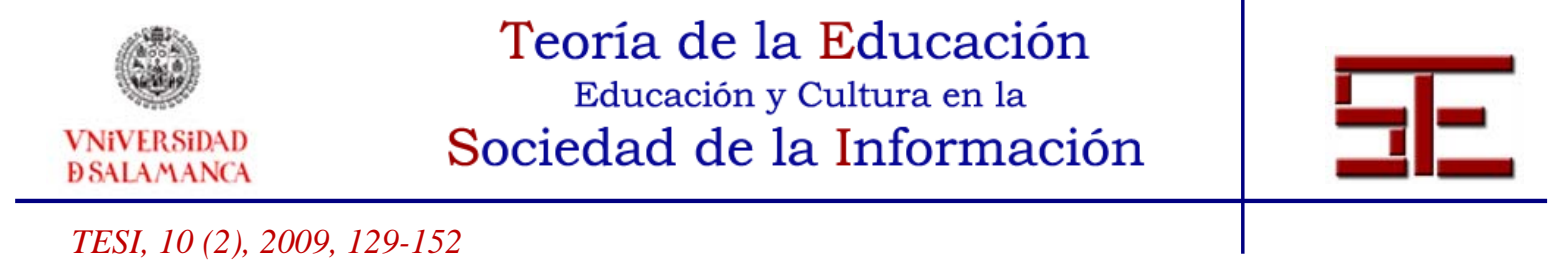

MEC (2005): Una Educación de calidad para todos y entre todos. Informe del debate. Madrid, Secretaría General Técnica.

MEC (2005): Objetivos educativos europeos y españoles. Puntos de referencia 2010. Madrid, Secretaría General Técnica.

ORTEGA NAVAS, $\mathrm{M}^{\mathrm{a}}$ C. (2006): Dimensiones formativas de los medios de comunicación, en LÒPEZ-BARAJAS, E. et al. (2006): Estrategias de formación en el siglo XXI. Barcelona, Ariel, 223-244.

ORTEGA SÁNCHEZ, I. (2006): La alfabetización tecnológica y emocional, en LÒPEZ-BARAJAS, E. et al. Estrategias de formación en el siglo XXI. Barcelona, Ariel, 481-492.

RIOS ARIZA, J. M. y CEBRIÁN DE LA SERNA (Coords) (2000): Nuevas tecnologías de la información y de la comunicación aplicadas a la educación. Málaga, Aljibe.

RODRÍGUEZ DÍEGEZ, J. L. y SÁENZ BARRIO, O. (1995): Tecnología educativa. Nuevas tecnologías aplicadas a la educación. Alcoy, Marfil.

ROIG VILA, R. (2002): Nuevas tecnologías aplicadas a la educación. Elementos para una articulación didáctica de las tecnologías de la información y la comunicación. Alcoy, Marfil.

ROSENBERG, M. J. (2001) E-Learning: estrategias para transmitir conocimiento en la era digital. Bogota, McGraw-Hill Interamericana.

SEBASTIÁN, A. y SÁNCHEZ, M. F. (2000): El mercado de trabajo y el acceso al mundo laboral. Barcelona, Estel.

SELWIN, N. GORARD, S. y FURLONG, J. (2006): Adult learning in the digital age. Information technology and the learning society. London, Routledge.

TEJADA, J. (1999): El formador ante las TIC: nuevos roles y competencias profesionales, Comunicación y Pedagogía, 158, 17-26.

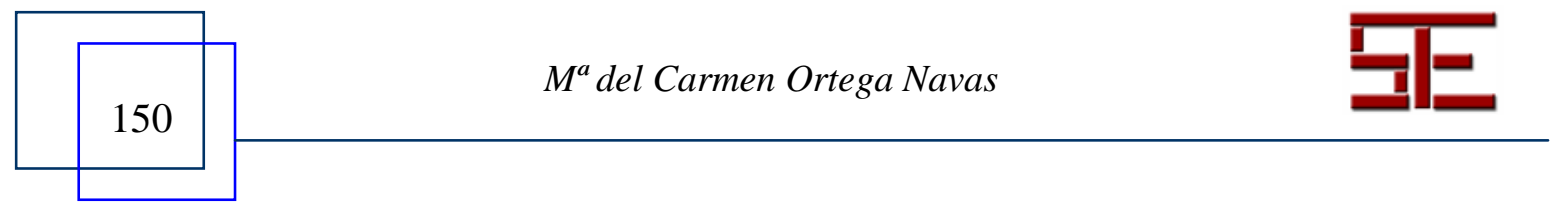




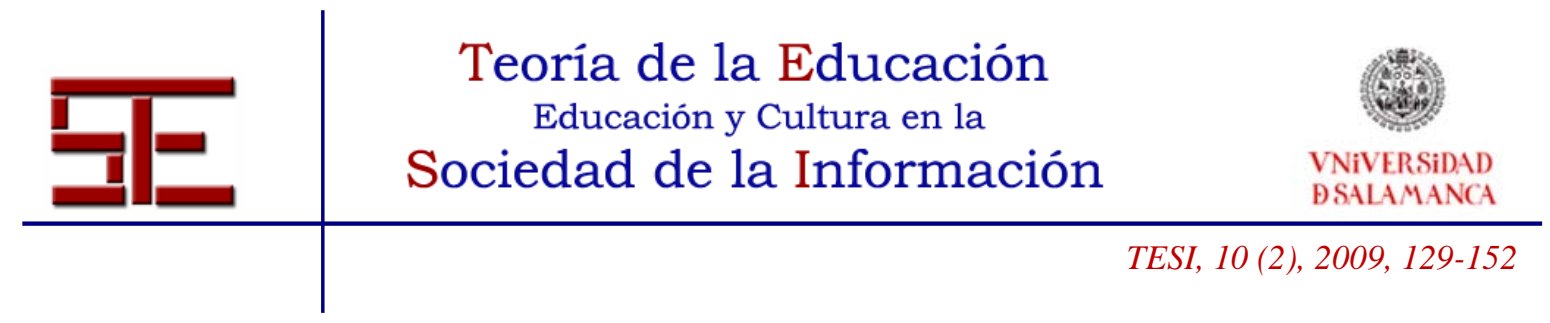

TOURIÑAN, J. M. (2001): Tecnología digital y sistema educativo: el reto de la globalización, Revista de Educación. Monográfico Globalización y Educación. Ministerio de Educación, Cultura y Deporte.

UNESCO (1998): Informe mundial sobre la educación 1998. Los docentes y la enseñanza en un mundo en mutación. París, Santillana-UNESCO.

UNESCO (1999): Declaración sobre la Ciencia y la utilización del conocimiento científico, en Conferencia Mundial la Ciencia para el siglo XXI: Un nuevo compromiso. [Fecha de consulta: 17.11.08] http://www.unesco.org./

UNESCO (2000): Declaración Mundial sobre Educación para Todos. [Fecha de consulta: 11.11.08] http:// www.unesco.org./

UNESCO (2005): Hacia las sociedades del conocimiento. París, Organización de las Naciones Unidas para la Educación, la Ciencia y la Cultura.

UNESCO (2006): La alfabetización, un factor vital. Informe del seguimiento de la EPT en el mundo París, Organización de las Naciones Unidas para la Educación, la Ciencia y la Cultura.

UNESCO (2008): Estándares de competencia en TIC para docentes (ECD-TIC), Organización de las Naciones Unidas para la Educación, la Ciencia y la Cultura. [Fecha de consulta: 20.11.08] http://www.miescuelayelmundo.org/IMG/pdf/UNESCO EstandaresDocentes.pdf

WATSON M. (2001): Pedagogy before Technology: Re-thinking the Relationship between ICT and Teaching, Education and Information Technologies, 6 (4), 251266.

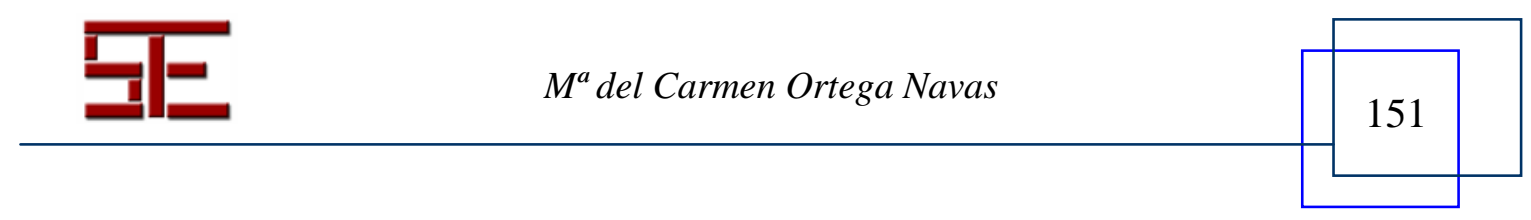




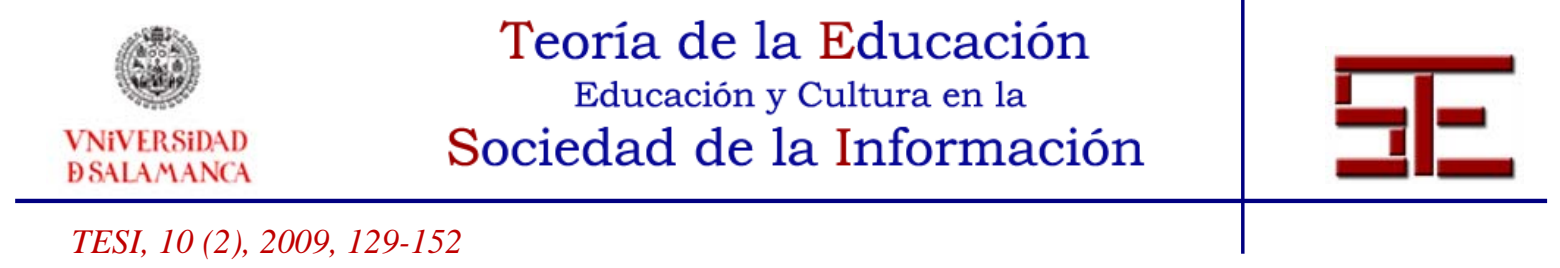

Para citar la presente editorial puede utilizar la siguiente referencia:

Ortega Navas, C. (2009). Dimensión formativa de la alfabetización tecnológica, en Ortega Sánchez, I. Ferrás Sexto, C. (Coord.) Alfabetización Tecnológica y desarrollo regional [monográfico en línea]. Revista Electrónica Teoría de la Educación: Educación y Cultura en la Sociedad de la Información. Vol. 10, no 2. Universidad de Salamanca [Fecha de consulta: $\mathrm{dd} / \mathrm{mm} / \mathrm{aaaa}$.

http://campus.usal.es/ revistas_trabajo/index.php/revistatesi/article/view/7511/7542 